\title{
Extraskeletal Osteochondroma Arising on the Plantar Region
}

\section{Takashi Ueno Shin-ichi Ansai Tokuya Omi Seiji Kawana}

Department of Dermatology, Musashi-Kosugi Hospital, Nippon Medical School, Kawasaki, Japan

\section{Key Words}

Extraskeletal osteochondroma $\cdot$ Extraskeletal chondroma $\cdot$ Soft-tissue chondroma $\cdot$ Foot

\begin{abstract}
Extraskeletal osteochondroma is a variant of extraskeletal chondromas that are uncommon soft-tissue cartilaginous tumors. These tumors may undergo extensive enchondral ossification to form an extraskeletal osteochondroma. This report describes the case of a 39-year-old Japanese man with an extraskeletal osteochondroma arising on the plantar aspect of the foot.
\end{abstract}

\section{Introduction}

Extraskeletal chondromas are uncommon soft-tissue tumors, occurring in extraosseus and extrasynovial structures, predominantly composed of mature hyaline cartilage $[1,2]$. Extraskeletal osteochondroma is a variant of those, which has undergone extensive enchondral ossification $[1,2]$. This article presents a case of an extraskeletal osteochondroma arising on the plantar region.

\section{Case Report}

A 39-year-old Japanese male presented with a nodule on his left foot that had been present for 15 years. The patient felt gradually increasing pain while ambulating. He had no memory of any injury to the region. A clinical examination revealed a nodule measuring $2.0 \mathrm{~cm}$ in diameter, with tylosis on the surface, located on the plantar aspect of the left forefoot (fig. 1a). The nodular lesion was well confined, smooth, hard, and held in place by the basement structures. There was no translucency through the tumor, and the patient experienced tenderness during the examination. Routine laboratory tests were within normal limits. Magnetic resonance imaging (MRI) showed a well-defined mass located in the subcutaneous soft tissues of the plantar aspect of the foot between the third and forth metatarsal heads, measuring $1.3 \mathrm{~cm}$ in diameter, with hypointensity on both $\mathrm{T}_{1}$ - and $\mathrm{T}_{2}$-weighted images (WI) (fig. 2).

The tumor was completely resected under local anesthesia, revealing a demarcated yellowish lobulated mass with a thin capsule loosely connected to the plantar aponeurosis and adjacent to the 
tendon sheath of the third-toe flexor tendon, but without any adhesion to the bone (fig. $1 \mathrm{~b}$ ). The histological examination revealed a circumscribed lobulated nodular lesion covered with a fibrous capsule (fig. 3i $)$. The tumor was composed of cartilaginous matrices (fig. 3b) with prominent ossification (fig. 3c) and contained chondrocytes embedded in cartilage at the periphery of the lesion (fig. 3d). No mitotic figures were present. The histological findings were consistent with those of extraskeletal osteochondroma, a variant of extraskeletal chondroma with extensive enchondral ossification. No recurrence has been observed after 2 years.

\section{Discussion}

Extraskeletal chondromas, synonymous with soft-tissue chondromas or chondromas of soft parts, are slow-growing well-defined solitary nodules of hyaline cartilage $[1,2]$. They usually arise adjacent to periarticular tissues or tenosynovium but not attached to the intra-articular synovium or periosteum by definition [1]. Kransdorf and Meis [3] reported that extraskeletal chondroma represented 276 of 18,771 cases (1.5\%) of all benign soft-tissue tumors examined at their institute (AFIP: Armed Forces Institute of Pathology). They are slow growing and rarely exceed $3 \mathrm{~cm}$ in diameter $[1,2]$. Twenty percent of the patients with extraskeletal chondroma present with pain or tenderness, especially located in the plantar region or finger $[4,5]$. Chung and Enzinger [6] surveyed the 104 cases of extraskeletal chondromas referred to AFIP and reported that they usually occur in patients in their thirties or forties, ranging from 9 to 78 years of age and that the most affected site was the fingers (49\%), followed by the hands (15\%), toes (11\%), feet (10\%), forearms (4\%) and other sites.

Hondar $\mathrm{Wu}$ et al. [7] reported that extraskeletal chondromas usually show intermediate signal intensity on $\mathrm{T}_{1} \mathrm{WI}$ and high signal intensity on $\mathrm{T}_{2} \mathrm{WI}$ in most MRI studies, and such high signal intensity is due to the high water content of the cartilage. However, they also noted that the major part of the chondroma in one case showed hypointensity both on $\mathrm{T}_{1}$ and $\mathrm{T}_{2} \mathrm{WI}$ as suggested in the present case. Those findings were ascribed to dense calcification, indicating that MRI of extraskeletal chondroma can vary in relation to the content and degree of calcification in the tumor [7], while others report that the diagnosis can be made based on MRI $[1,5]$.

Extraskeletal chondromas can undergo extensive enchondral ossification, and then such lesions are designated extraskeletal osteochondromas [1,2]. The term 'extraskeletal osteochondroma' should not be confused with 'osteochondroma', one of the most common benign bone tumors, accounting for $40 \%$ of tumors seen in flat bones and at the end of long bones, also referred to as an exostosis $[8,9]$.

Local excision is the standard treatment for extraskeletal chondromas [2]. The local recurrence rate is $15 \%[2,6]$. Recurrent tumors are usually treated by re-excision $[2,4]$. Although some extraskeletal chondromas show atypical cellular features, these tumors are benign [2].

The present case showed the typical epidemiology, site of involvement and clinical features of extraskeletal chondromas. The lesion had some unusual features and was diagnosed to be an extraskeletal osteochondroma because of extensive enchondral ossification, which presented as hypointensity on $\mathrm{T}_{1}$ and $\mathrm{T}_{2}$ WI MRI due to considerable calcification, unlike ordinary extraskeletal chondromas. 

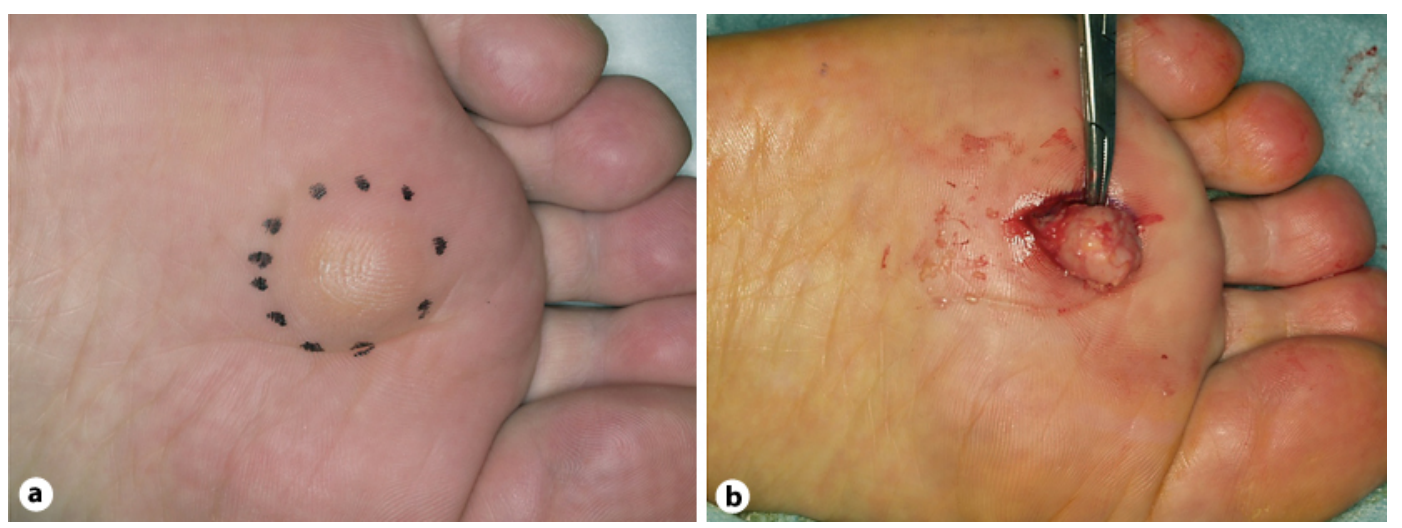

Fig. 1. a A nodular lesion with tylosis on the surface, located on the plantar aspect of the left forefoot.

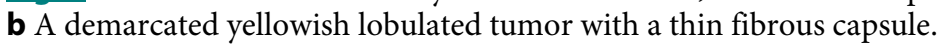
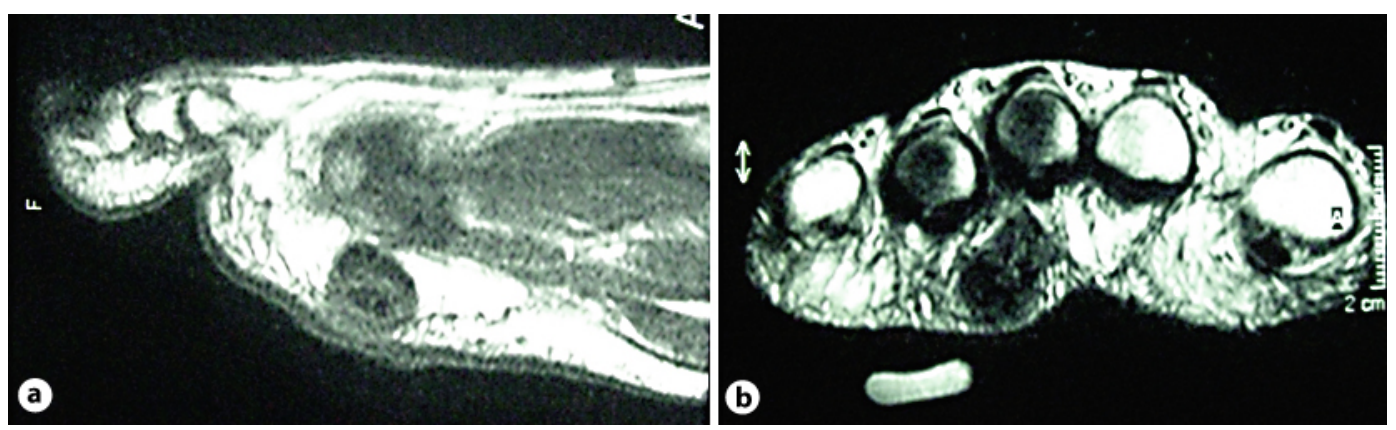

Fig. 2. MRI showing a well-defined mass located in the subcutaneous soft tissues of the plantar aspect and no evidence of connection to the bone. The MRI signal of the lesion showed hypointensity on both $\mathrm{T}_{1^{-}}$(a) and $\mathrm{T}_{2}$-weighted (b) images. 


\begin{tabular}{|c|c|c|c|}
\hline $\begin{array}{l}\text { Case Reports in } \\
\text { Jermatology }\end{array}$ & $\begin{array}{l}\text { Case Rep Dermatol 2011;3:147-150 } \\
\text { DOI: } 10.1159 / 000330459 \\
\end{array}$ & \begin{tabular}{|l} 
Published online: \\
July 20, 2011
\end{tabular} & \begin{tabular}{|l} 
@ 2011 S. Karger AG, Basel \\
ISSN 1662-6567 \\
www.karger.com/cde
\end{tabular} \\
\hline
\end{tabular}
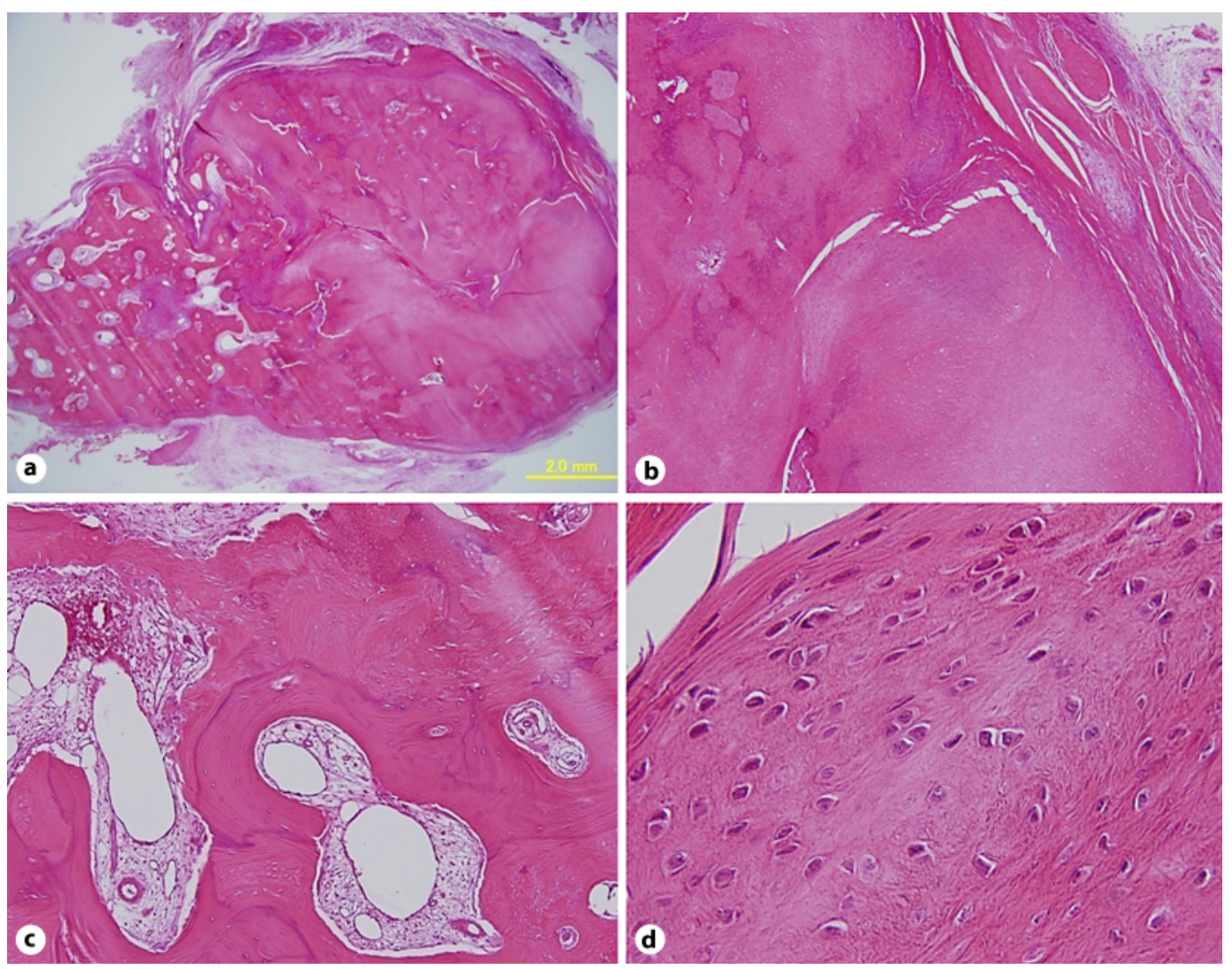

Fig. 3. Findings of an HE-stained specimen. a Low magnification revealed a circumscribed lobulated nodular lesion covered with a fibrous capsule (original magnification, $\times 12.5$ ). $\mathbf{b}$ The lesion contained mature hyaline cartilage (original magnification, $\times 40$ ). $\mathbf{c}$ The tumor shared extensive ossification (original magnification, $\times 200$ ). d There were chondrocytes embedded in cartilage at the periphery of the lesion (original magnification, $\times 400$ ).

\section{References}

1 Nayler S, Heim S: Soft tissue chondroma; in Fletcher CD, Krishnan Unni K, Mertens F (eds): Pathology and Genetics of Tumours of the Soft Tissues and Bones (World Health Organization Classification of Tumours). Lyon, IARCPress, 2002, pp 180-181.

2 Weiss SW, Goldblum JR: Cartilaginous soft tissue tumors; in Weiss SW, Goldblum JR (eds): Enzinger and Weiss's Soft Tissue Tumors, ed 5. St. Louis, Mosby, 2007, pp 1017-1036.

3 Kransdorf MJ, Meis JM: From the archives of the AFIP. Extraskeletal osseous and cartilaginous tumors of the extremities. Radiographics 1993;13:853-884.

-4 Papagelopoulos PJ, Savvidou OD, Mavrogenis AF, Chloros GD, Papaparaskeva KT, Soucacos PN: Extraskeletal chondroma of the foot. Joint Bone Spine 2007;74:285-288.

5 Wong L, Dellon AL: Soft tissue chondroma presenting as a painful finger: diagnosis by magnetic resonance imaging. Ann Plast Surg 1992;28:304-306.

6 Chung EB, Enzinger FM: Chondroma of soft parts. Cancer 1978;41:1414-1424.

7 Hondar Wu HT, Chen W, Lee O, Chang CY: Imaging and pathological correlation of soft-tissue chondroma: a serial five-case study and literature review. Clin Imaging 2006;30:32-36.

8 Sheff JS, Wang S: Extraskeletal osteochondroma of the foot. J Foot Ankle Surg 2005;44:57-59.

9 Chin KR, Kharrazi FD, Miller BS, Mankin HJ, Gebhardt MC: Osteochondromas of the distal aspect of the tibia or fibula. Natural history and treatment. J Bone Joint Surg Am 2000;82:1269-1278. 